\title{
Determination of Antioxidant Flavonoids in Sudanese Honey Samples by Solid Phase Extraction and High Performance Liquid Chromatography
}

\author{
SUZAN ZEIN ALABDEEN MAKAWI, \\ ELRASHEED AHMED GADKARIEM ${ }^{\S}$, \\ and SAAD MOHAMED HUSSEIN AYOUB*
}

\author{
Central Laboratory, Ministry of Science and Technology, Sudan. \\ ${ }^{\S}$ Faculty of Pharmacy, El-ribat NationalUniversity, Khartoum,Sudan. \\ *Faculty of Science and Technology, Alneelain University, Khartoum, Sudan. \\ suzanmakawi@yahoo.com
}

Received 22 December 2008; Accepted 24 February 2009

\begin{abstract}
Flavonoids were extracted by solid phase extraction (SPE) from seven floral honey samples of different botanical origin from different regions of Sudan. The flavonoids were determined by high performance liquid chromatography (HPLC) technique using photo diode array detector (PDA). An isocratic and gradient systems for the resolution, identification and quantification of five flavonoids, namely; quercetin, kaempferol, apigenin, hesperetin and isorhamnetin, were developed. Although the isocratic system resolved the five compounds, however it suffered from interference by the complex mixture of honey samples. The gradient system resolved three of five flavonoids, namely, quercetin, kaempferol, and isorhamnetin, without interference by the complex honey matrix. Two flavonoids, apigenin and hesperetin, were observed to elute at close retention times, which lead to their interference with each other when injected in a mixture; however, absorption wavelength selection was found indicative of the presence or absence of either compound. The quantification of these flavonoids was done through the calibration curves of their standards. The obtained results were compared with reported results.
\end{abstract}

Keywords: Honey, Flavonoids, Sudan, SPE, HPLC.

\section{Introduction}

Honey is the most important primary product of beekeeping quantities, from both a quantitative and an economic point of view. It was also the first bee product used by human kind in ancient times. The history of the use of honey is parallel to the history of man. It is the natural sweet substance produced by honey bees from nectar of blossoms or from secretions of living parts of plants. 
Honey bees make honey to use and store as food, and humans exploited these trails. It was probably discovered by humans tasting the sweet substance in honey combs from the hollows of a tree, log, or cave. Thus, it is one of earliest forms of sweeteners and long precedes the use of cane and beet sugar ${ }^{1}$. Beekeeping for the purpose of obtaining honey is an ancient art, at least as early as the Egyptians (2000-5000 years ago) who used honey in medicine, and nutrition.

The chemical composition of honey is complex, and according to the earlier report ${ }^{2}$, it contains about 181substances, including sugars, proteins moisture, vitamins, minerals, hydroxymethylfurfural (HMF), enzymes, flavonoids, phenolic acids, volatile compounds etc., However, the main constituents of honey are moisture, glucose, fructose, sucrose, minerals, and proteins ${ }^{3}$.

Honey has been used since ancient times as a remedy for burns, cataracts, ulcers and wound healing, because it has a smoothing effect during its initial application to open wounds. It provides a protective barrier, owing to its high osmolarity, and creates a moist wound-healing environment in the form of a solution that does not stick to wounded tissues. This moist wound environment is believed to prevent bacterial colonization, and it is believed, that honey reduces inflammation and also reduces exudates formation more promptly than standard treatments ${ }^{1}$.

The antioxidant properties of honey are well known, because it contains a number of compounds with antioxidant properties such as, flavonoids, phenolic acids, proteins, amino acids, ascorbic acid, HMF, and some enzymes ${ }^{4}$. The most important classes of antioxidant polyphenols are the flavonoids and phenolic acids; it is these substances in tea, wine, fruits and vegetables that are most responsible for the antioxidant characteristics, and thus the healthy image of these foods.

Sudan, the largest country in Africa, with its different climatic conditions ranging from Sahara and sub-Sahara, savannah and tropical regions possesses a tremendous wealth of terrestrial plants which contribute to the economy of the country. Medicinal plants represent an important part of these resources with great potentialities and research in this field is encouraged by different institutions in public and private sectors. Sudanese floral honey in the last decades gained a solid ground and interest in the field of commerce and research, but the available honey products of different origins lack documentation in the literature about their composition and properties. The present research was undertaken to spot more light on the composition of floral honeys from different regions in Sudan with emphasis on their antioxidant polyphenols. While there are various types of antioxidants naturally occurring in honey as mentioned previously, this study focuses only on the flavonoids.

Honey flavonoids can originate from nectar, pollen or propolis. Propolis, being a natural constituent of honeycombs, has components that are probably distinguished between the relatively lipophilic beeswax and the more hydrophilic honey ${ }^{5}$. As the flavonoids are relatively lipophilic, their concentration in honey is much lower than that in propolis ${ }^{6}$. Only flavonoid aglycones (without sugar moieties) seem to be present in propolis and honey, while honeybee pollen contains flavonol in herosidic forms ${ }^{7}$. The flavonoids in honey and propolis have been identified as flavanones and flavanols ${ }^{7}$. In general, the flavonoid concentration ${ }^{8}$ in honey is approximately $20 \mathrm{mg} / \mathrm{kg}$. Unlike flavonoids in nectar or pollen, some of the flavonoids found in honey are aglycones with an unsubstituted B ring 9 . Scheme 1 shows the general structure of flavonoids. Compounds in honey that have been identified include flavones such as Apigenin; flavonols such as kaempferol; flavavones such as hesperetin; and phenolic acids. 


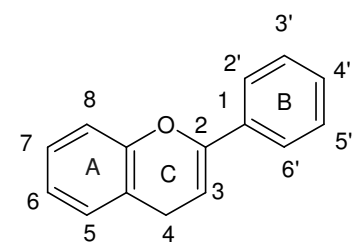

Figure 1. General structure of flavonoids.

Most studies have focused on the analysis of honey flavonoids by using the high performance liquid chromatography (HPLC) methods. HPLC was first used for the determination of flavonoids in 1976 by fisher and Wheaton ${ }^{10}$. UV with photodiode array (PDA) detection is the standard method used for the detection of flavonoids. Since flavonoids are polyphenols, two UV absorption bands are characteristic of this type of compounds. Band 2, with a maximum in the $240-285 \mathrm{~nm}$ range, is believed to arise from the (A) ring, whereas band 1 with a maximum in the $300-550 \mathrm{~nm}$ range, presumably arises from the (B) ring ${ }^{10}$. Quantification of flavonoids is another advantage of HPLC with UV detection. A good estimate of the flavonoid concentration can be determined by comparing integration data for the honey chromatogram with that for a known amount of a readily available standard $^{10}$. In this study we identified and quantified: quercetin, kaempferol, apigenin, hesperetin and isorhamnetin, in different honey samples.

\section{Experimental}

\section{Honey samples}

Most of the samples were collected and processed by Kingdom Co. (Sudan-khartoum). The honey samples namely, Alradoom, Blue nile, Jabal mara, sidir, sun flower, sunnut and Talih, were collected from different regions of Sudan:

- Alradoom sample: source: west of Sudan (Alradoom). Honey was collected during winter, 2006.

- Blue Nile sample: source: south east of Sudan (Aldamazeen). Honey was collected during winter, 2006.

- Jabal marra sample: source: west of Sudan (Jabal marra). Honey was collected during winter, 2006.

- Sidir sample: (Ziz phus spina-christi, family Rhamnaceae) source: south east of Sudan (Aldinder). Flowering stage: early September to mid November. Honey was collected in late November, 2006.

- Sun flower sample :( Helinathus annuus, family Asteraceae) source: south east of Sudan (Singa), flowering stage: late March to mid May. Honey was collected in late May, 2006.

- Sunnut sample :( Acacia nilotica, subsp nilotica, family Mimosaceae), source: south east of Sudan (Singa), flowering stage: early July to mid September. Honey was collected in late September 2006.

- Talih sample: (Acacia Seyal subsp seyal, family Mimosaceae), source: east of Sudan (Aldindir). Flowering stage: mid January to March. Honey was collected in late March, 2006.

\section{Solvents and chemicals}

- Acetonitrile HPLC grade (99.8\%), from Scharlau / Spain.

- Methanol HPLC grade (99.9\%), from Scharlau / Spain. 
- $\quad$ Apigenin HPLC grade - from Applichem / Germany

- Hesperetin HPLC grade - from Applichem / Germany.

- Isorhamnetin HPLC grade - from Applichem / Germany.

- Quercetin HPLC grade - from Applichem / Germany.

- All other chemicals used were either of analytical grade or general purpose reagents.

\section{Preparation of standards}

The stock solution $(1000 \mu \mathrm{g} / \mathrm{mL})$ for each standard was prepared by weighing $25 \mathrm{mg}$ of standard, dissolved in methanol (in acetonitrile for kaempferol) and the volume completed to $25 \mathrm{~mL}$ in volumetric flask with methanol. The working standard solutions were prepared by diluting the stock solution $(1000 \mu \mathrm{g} / \mathrm{mL})$ to contain concentrations $2.5 \mu \mathrm{g} / \mathrm{mL}, 50 \mu \mathrm{g} / \mathrm{mL}$ and $100 \mu \mathrm{g} / \mathrm{mL}$ for quercetin, and $5 \mu \mathrm{g} / \mathrm{mL}, 25 \mu \mathrm{g} / \mathrm{mL}, 50 \mu \mathrm{g} / \mathrm{mL}$ and $100 \mu \mathrm{g} / \mathrm{mL}$ for each of kaempferol, hesperetin, apigenin and isorhamnetin.

\section{Preparation of honey samples}

Five grams of all honey samples were dissolved in $10 \mathrm{~mL}$ deionized water, adjusted to $\mathrm{pH} 2$ with $\mathrm{HCl}(1 \mathrm{~N})$, and passed through the solid phase extraction (SPE) Column $\left(\mathrm{C}_{18}\right)-500 \mathrm{mg}$.

\section{SPE procedure}

Column preparation: The $\mathrm{C}_{18}$ column was rinsed with $3 \mathrm{~mL}$ methanol HPLC grade $+3 \mathrm{~mL}$ acetonitrile (HPLC grade) $+3 \mathrm{~mL}$ deionized water at a flow rate $1 \mathrm{~mL} / \mathrm{min}(9 \mathrm{~mL}$ of this solvent in $9 \mathrm{~min}$ ), the column was then rinsed with $3 \mathrm{~mL}$ of deionized water (at $\mathrm{pH}=2)+10$ $\mathrm{mL}$ of deionized water at a flow rate $1 \mathrm{~mL} / \mathrm{min}$ (13 $\mathrm{mL}$ of this solvent in $13 \mathrm{~min}$ ).

Sample purification or clean-up process: Samples were applied at top of the column and the solvents were drawn through the column bed by a syringe. The column was washed with $3 \mathrm{~mL}$ deionized water (at $\mathrm{pH}=2)+10 \mathrm{~mL}$ deionized water at $1 \mathrm{~mL} / \mathrm{min}$ flow rate. The adsorped materials were then collected by $2 \mathrm{~mL}$ methanol (HPLC grade) $+1 \mathrm{~mL}$ acetonitrile (HPLC grade) at $1 \mathrm{~mL} / \mathrm{min}$ flow rate. The samples were filtered through a $0.45 \mu \mathrm{m}$ membrane syringe filter, and collected in a $10 \mathrm{~mL}$ glass vial, and kept in the refrigerator for HPLC analysis.

\section{HPLC Conditions}

The chromatographic separation was conducted using an isocratic and gradient systems.

\section{The gradient system}

The standard mixtures (50 $\mu \mathrm{L}$ from each standard) and the cleaned honey samples, were analysed using a Waters (600) HPLC linked with a computer-controlled system. Sample $(20 \mu \mathrm{L})$ was injected using a manual injector. The flavonoids were detected using a waters (2996) photodiode array detector (PDA), the column used was a reversed phase $\mathrm{C}_{18}$ column $(15 \mathrm{~cm} \times 0.46 \mathrm{~cm})$. For analysis by (PDA) detection, UV spectra were recorded from $210-400 \mathrm{~nm}$ at a resolution $1.2 \mathrm{~nm}$. In particular, the chromatograms were monitored at $340 \mathrm{~nm}$ and $290 \mathrm{~nm}$. The mobile phase was composed of $5 \%$ acetic acid in deionized water (solvent A), and acetonitrile HPLC grade (solvent B), at a constant solvent flow rate $1 \mathrm{~mL} / \mathrm{min}$.

- $\quad$ Solvent $A=5 \%$ acetic acid in deionized water

- $\quad$ Solvent B = Acetonitrile HPLC grade (99.8\%).

The following gradient was used: 
Table 1. The gradient system.

\begin{tabular}{cccc}
\hline Time, $\min$ & Flow, $\mathrm{mL} / \mathrm{min}$ & $\mathrm{A}, \%$ & $\mathrm{~B}, \%$ \\
\hline Initial & $1: 00$ & 95 & 5 \\
15 & $1: 00$ & 85 & 15 \\
25 & $1: 00$ & 85 & 15 \\
40 & $1: 00$ & 78 & 22 \\
70 & $1: 00$ & 78 & 22 \\
80 & $1: 00$ & 75 & 25 \\
90 & $1: 00$ & 95 & 5 \\
\hline
\end{tabular}

The isocratic system

The mobile phase was composed of $5 \%$ acetic acid in deionized water (solvent A), and methanol HPLC grade (solvent B), at a flow rate $1.5 \mathrm{~mL} / \mathrm{min}$.

$$
\begin{aligned}
& \text { Solvent }(A)=65 \% \\
& \text { Solvent }(B)=35 \%
\end{aligned}
$$

\section{Identification and quantification of flavonoids in honey samples extracts}

The mentioned flavonoids were identified and quantified according to the gradient system. In order to identify each peak in the chromatograms of honey extracts, retention times of all peaks were compared with those of flavonoid standards. The flavonoids were quantified using external standard method (Three to five working standards of quercetin, hesperetin, kaempferol, apigenin and isorhamnetin). A plot of peak heights against concentration of each standard was done. Regression analysis data were obtained. The standards (quercetin, kaempferol, apigenin and isorhamnetin) were recorded at $340 \mathrm{~nm}$, while hesperetin was recorded at $290 \mathrm{~nm}$. The flavonoids were quantified against their respective standards

\section{Results and Discussion}

Honey samples are expected to be composed of a complex matrix with different uvabsorbing compounds (flavonoids and phenolic acids), therefore only a separating method is likely to resolve such complex matrix. This could be done using HPLC method at an isocratic mode or more probably at a gradient mode. In this study both isocratic and gradient separations were tried. Out of the studied isocratic systems, the use of $65 \% \mathrm{v} / \mathrm{v}$ of $5 \%$ acetic acid in water and $35 \% \mathrm{v} / \mathrm{v}$ methanol was found to give the best resolution between these five studied standards; however the eluting peaks were showing front tailing besides the overlapping observed when honey samples were injected. On the other hand the gradient system (Table 1 \& Figure 2) showed reasonable resolution for three of the studied standards (quercetin, kaempferol and isorhamnetin) and some overlap between apigenin and hesperetin. The problem of the co-eluting peaks (hesperetin-apigenin) was not possible to solve, although different gradient systems were tried. However the study of their UV-absorption revealed that hesperetin has low intensity of absorption at $340 \mathrm{~nm}$ (Figure 3A), and high absorption at $290 \mathrm{~nm}$ (Figure 3B). Apigenin and the other standards showed the reversed phenomena; this was found useful for the assay of hesperetin at $290 \mathrm{~nm}$ where the interfering apigenin has very low absorption, besides this fact, hesperetin is found at very low concentration in honey samples, and therefore it is expected to have negligible interference in the assay of apigenin at $340 \mathrm{~nm}$ (Figure 4). 


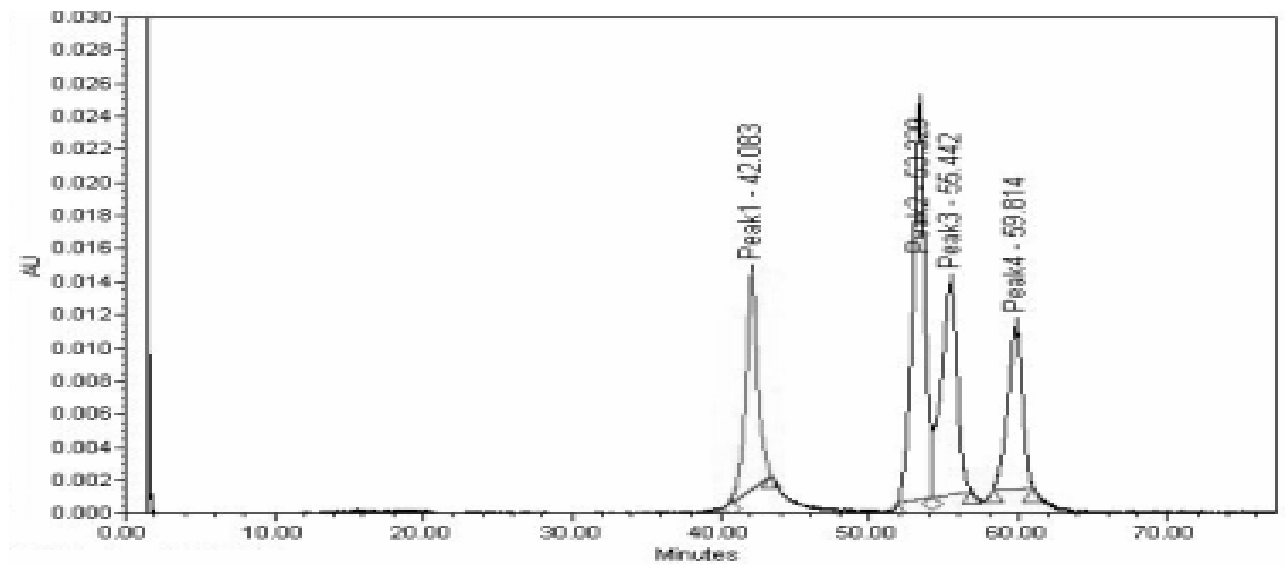

Figure 2. Mixture of five standards at $340 \mathrm{~nm}$.

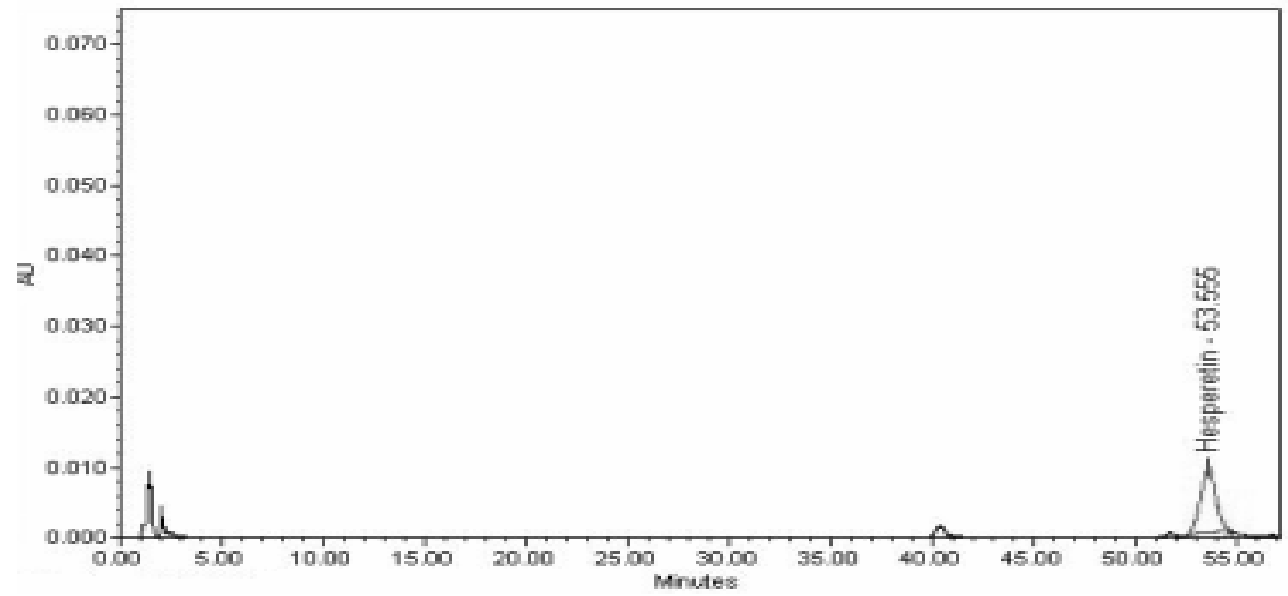

Figure 3A. Standard of hesperetin at $340 \mathrm{~nm}$

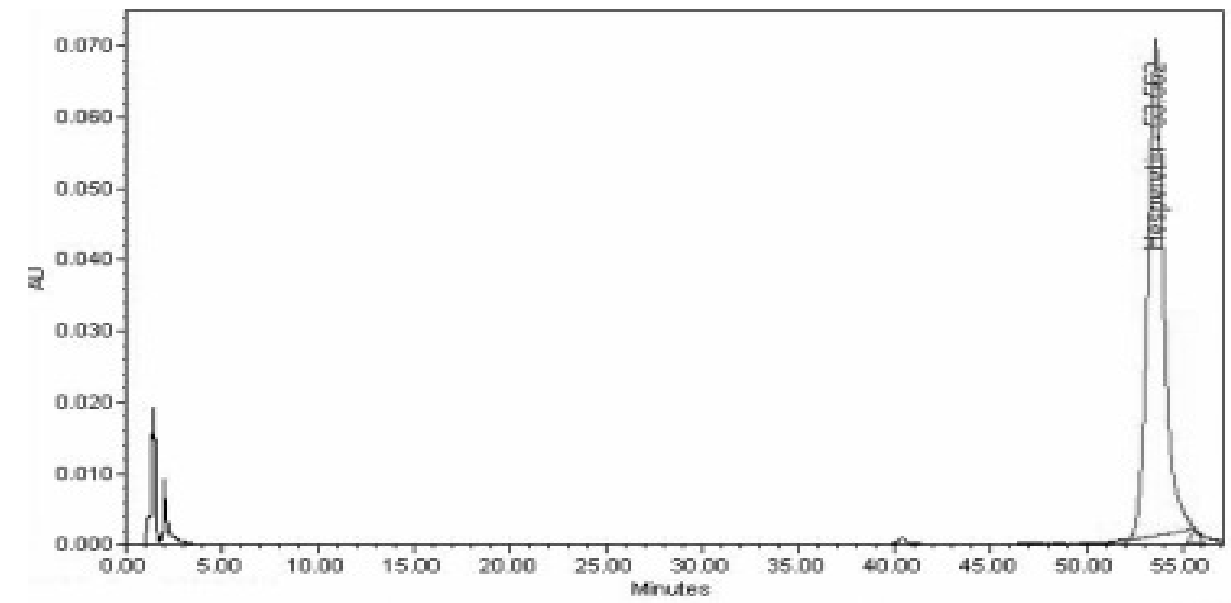

Figure 3B. Standard of hesperetin at $290 \mathrm{~nm}$. 


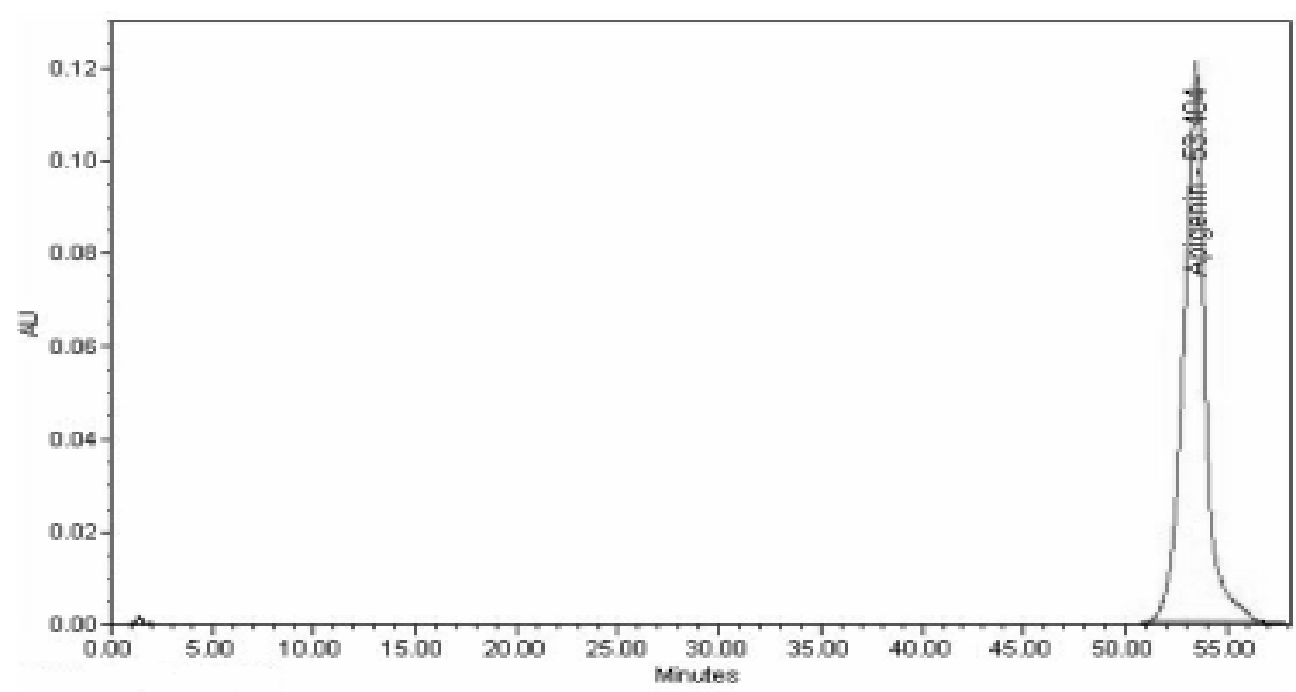

Figure 4. Standard of Apigenin at $340 \mathrm{~nm}$.

\section{HPLC-analysis of honey samples}

The main problem in the analysis of flavonoids from honey is the very high sugar content, which makes the extraction of flavonoids and sample preparation for HPLC analysis difficult ${ }^{8}$. Liquid-liquid partitions produce inconvenient interphases which do not permit the complete recovery of flavonoids. However, this problem has been solved by using $\mathrm{XAD}_{2} \mathrm{Resin}^{8}$. In this study we used the solid phase extraction (SPE) process instead of the $\mathrm{XAD}_{2}$ Resin. Solid phase extraction (SPE) technique has been developed to replace traditional liquid-liquid extraction methods for the determination of organic analytes in aqueous samples. The acidified honey solution was passed through column $\mathrm{C}_{18}(500 \mathrm{mg})$, and the column was washed with water to extract the polar fraction of honey, and then the non-polar fraction (flavonoids \& phenolic acids) was eluted from the cartridge with $3 \mathrm{~mL}$ of methanol and acetonitrile $(2: 1)$. Three, $20 \mu \mathrm{L}$ volumes were injected into the column and flavonoids content was calculated reference to each standard regression analysis data (Table 2).

Table 2. Standard regression analysis data.

\begin{tabular}{rrrr}
\hline Standard & $\mathrm{R}^{2}$ & $\mathrm{~A}$ & $\mathrm{~B}$ \\
\hline Quercetin & 0.9999 & 880 & 771 \\
Kaempferol & 0.9993 & 562 & 523 \\
Apigenin & 0.9998 & 1570 & 2170 \\
Hesperetin & 0.9992 & 1340 & 734 \\
Isorhamnetin & 0.9993 & 291 & 438 \\
\hline
\end{tabular}

\section{Identification and quantification of flavonoids in honey samples extracts}

In this study the chromatograms were monitored at 290 and $340 \mathrm{~nm}$, since majority of the honey flavonoids have their UV absorption maxima around these wave lengths (1).

\section{Alradoom sample}

The flavonoid compounds under study were not detected in this sample at $340 \mathrm{~nm}$ and $290 \mathrm{~nm}$. 


\section{Blue nile sample}

The flavonoids identified in Blue nile sample were quercetin, hesperetin, kaempferol, apigenin. The concentration of quercetin, kaempferol, apigenin were calculated at $340 \mathrm{~nm}$ and hesperetin at $290 \mathrm{~nm}$ using the calibration curve of these compounds.

\section{Jabal marra sample}

The flavonoids identified in Jabal marra sample were quercetin, isorhamnetin. The concentration of quercetin and isorhamnetin were calculated at $340 \mathrm{~nm}$ using the calibration data of these compounds.

Sidir sample (Zizphus spina-christi)

The flavonoid identified in Sidir sample was quercetin. The concentration of quercetin was calculated at $340 \mathrm{~nm}$ using the calibration data of quercetin. A comparison was done between Sidir sample studied flavonoids content and published data on sidir samples studied in Egypt (Table 3).

Table 3. Comparison of studied flavonoids content and published data.

\begin{tabular}{ccc}
\hline Flavonoids & Present study $^{*}$ & Published study $^{14}$ \\
\hline Quercetin & 154.7 & - \\
Hesperetin & - & 159.33 \\
Kaempferol & - & 20.07 \\
\hline \multicolumn{3}{c}{}
\end{tabular}

\section{Sun flower sample (Helinathus annuus)}

The flavonoids identified in sun flower sample were quercetin, kaempferol, apigenin, hesperetin and isorhamnetin. Hesperetin absorbs strongly at $290 \mathrm{~nm}$. The concentration of quercetin, kaempferol, apigenin, and isorhamnetin were calculated at $340 \mathrm{~nm}$ and hesperetin at $290 \mathrm{~nm}$ using the calibration data of these compounds. The comparison of results obtained in this study and Helianthus honey in study of Fast SPE Extraction and LC-ESI-MS-MS analysis of flavonoids and phenolic acids (Patrizio pulcini, Francesco Allegrini, Norma Festuccia 2006), is shown in Table 4.

Table 4. The comparison of results.

\begin{tabular}{lcc}
\hline Flavonoids & Present study & Published study $^{12}$ \\
\hline Quercetin & 69.9 & 131 \\
Hesperetin & 640.6 & 14 \\
Apigenin & 52.6 & 22 \\
Kaempferol & 535.3 & 167 \\
Isorhamnetin & 36.6 & - \\
\hline \multicolumn{3}{c}{ "Sun flower sample }
\end{tabular}

\section{Sunnut sample (Acacia nilotica)}

The flavonoid identified in sunnut sample was quercetin. The concentration of quercetin (Table 5) was calculated at $340 \mathrm{~nm}$ using the calibration data of quercetin. The comparison between sunnut sample and a published study in acacia honey appears in Table 5 .

\section{Talih sample (Acacia seyal)}

The flavonoid compounds under study were not detected in this sample at $340 \mathrm{~nm}$ or $290 \mathrm{~nm}$. Most of these samples seem to be very rich in different flavonoids and phenolic acids, which need reference standards or the use of HPLC/MS to identify. 
Table 5. Comparison between sunnut sample and a published study in acacia honey.

\begin{tabular}{lccc}
\hline \multicolumn{1}{c}{ Flavonoid } & Present study $^{*}$ & Published study $^{13}$ & Published study $^{14}$ \\
\hline Quercetin & 67.2 & 61 & 17.58 \\
Kaempferol & - & 45 & 2.36 \\
Apigenin & - & - & 0.12 \\
\hline
\end{tabular}

Table 6. Summary of the concentration of some flavonoids $(\mu \mathrm{g} / 100 \mathrm{~g})$ calculated in the studied honey samples.

\begin{tabular}{cccccccc}
\hline Flavonoids & Alradom & $\begin{array}{c}\text { Blue } \\
\text { Nile }\end{array}$ & $\begin{array}{c}\text { Jabal } \\
\text { marra }\end{array}$ & Sidir & $\begin{array}{c}\text { Sun } \\
\text { flower }\end{array}$ & Sunnut & Talih \\
\hline Quercetin & - & 320.5 & 1.8 & 154.7 & 69.9 & 67.2 & - \\
Hesperetin & - & 391.4 & - & - & 640.6 & - & - \\
Apigenin & - & 38.3 & - & - & 52.6 & - & - \\
Kaempferol & - & 39.9 & - & - & 535.3 & - & - \\
Isorhamnetin & - & - & 32.4 & - & 36.6 & - & - \\
\hline
\end{tabular}

In this study the content of the specific flavonoids studied were compared with some published results. We are aware of the possible significant differences in the content of these flavonoids with the compared results due to geographical and climatic differences. Actually there is no previous study done in this line in Sudan and we are planning to establish reference data for the flavonoids content in different samples in Sudan; therefore we consider this work as a preliminary study.

\section{Acknowledgements}

We are grateful to Prof. Abdel Rhim M AL Hussein for his help and support and to the staff of the central laboratory -Ministry of Science and Technology.

\section{References}

1 Coulston A M, Nutrition Today, 2000, 35(3), 96-100.

2 Al-mamary M, Al-Meeri A and Al-Habori M, Nutrition Research, 2002, 22(9), 1041-1047.

3 Kirk R S and Sawyer R, Sugars and preserves in Pearson's composition and analysis of foods, $9^{\text {th }}$ Edn, Longman Scientific and Technical, Essex, 1991.

4 Gheldof H and Engeseth N J, J Agri Food Chem., 2002, 50(10), 3050-3055.

5 Ferreres F, Ortiz A, Silva C, Garcia-Viguera C, Tomás-Barberán F A and Tomás-Lorente F, Zeitschrift für Lebensmittel- Unterssuchung und-Forschung, 1992, 194, 139-143.

6 Bogdanov S, J Apic Res., 1989, 28(1), 55-57.

7 Anklam E, Food Chemistry, 1998, 63(4), 549-562.

8 Ferreres F, Tomás-Barberán F A, Soler C, García-Viguera C, Ortiz A and TomásLorente F, Apidologie, 1994c , 25(1), 21-30.

9 Campos M, Sabatier S, Amiot M J and Aubert S, Planta Med., 1990, 56, 580-581.

10 Sivam G, Analysis of Flavonoids, in W J Hurst (Ed), Methods of analysis for functional foods and nutraceuticals, CRC Press, Baca Raton, 2002.

11 Bruce R D' Arcy, Antioxidants in Australian floral honey, The Rural Industries Research and Development Corporation, Australian, 2005.

12. Patrizio Pulcini, Francesco Allegrini and NormaFestuccia, Apiacta, 2006, 41, 21-27.

13. Nele Gheldof, Xiao-Hong Wang and Nicki J Engeseth, J Agric Food Chem., 2002, 50, 5870-5877.

14. Ahmed G Hegazi and Faten K Abd El Hady, Department of Zoontic Diseases of Natural Product, National Research Center Dokki, Egypt, 2006. 


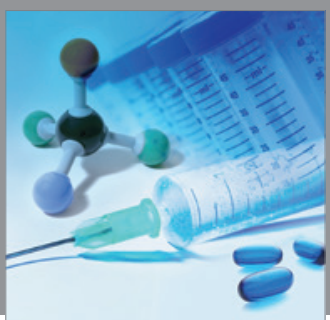

International Journal of

Medicinal Chemistry

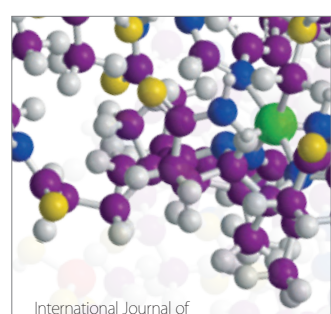

Carbohydrate Chemistry

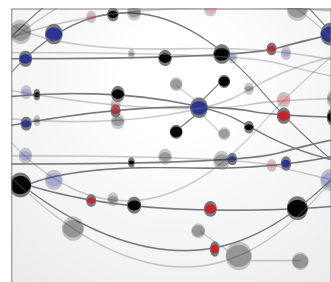

The Scientific World Journal
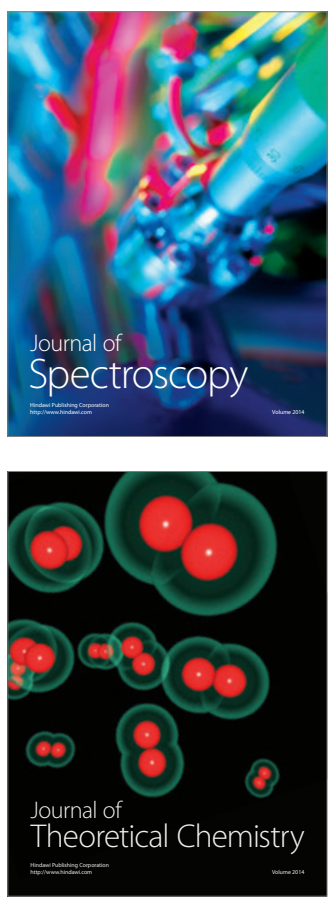
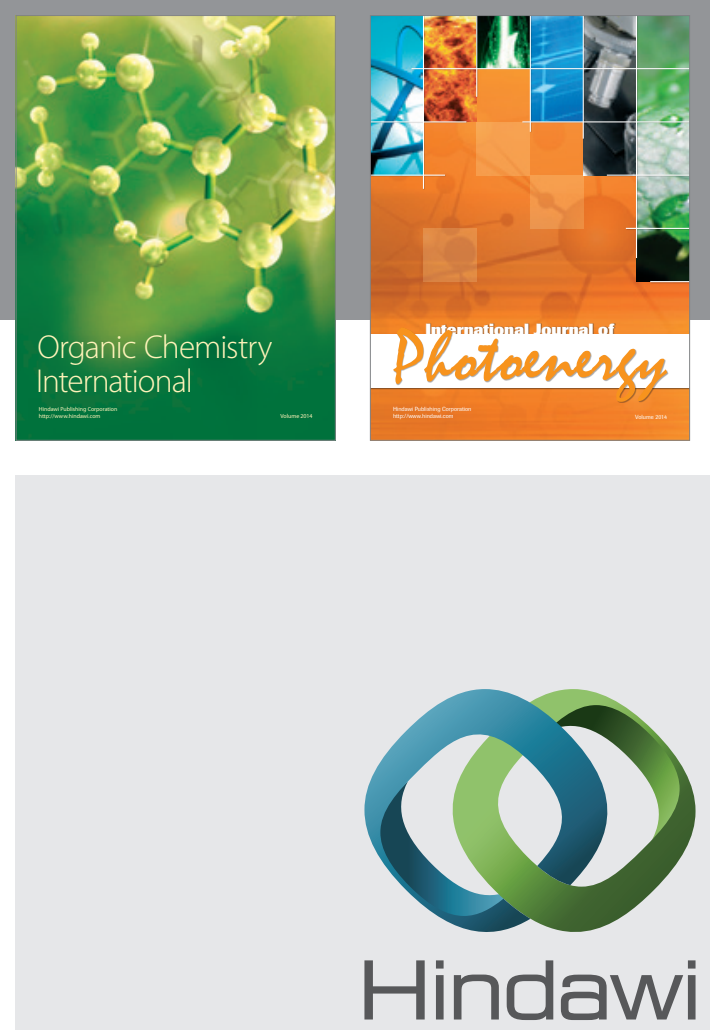

Submit your manuscripts at

http://www.hindawi.com
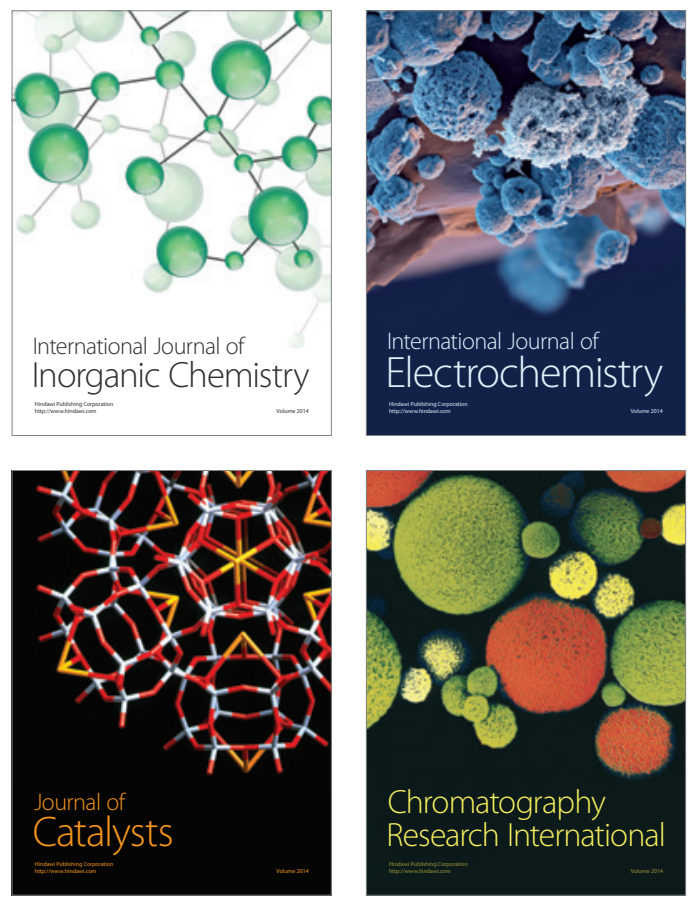
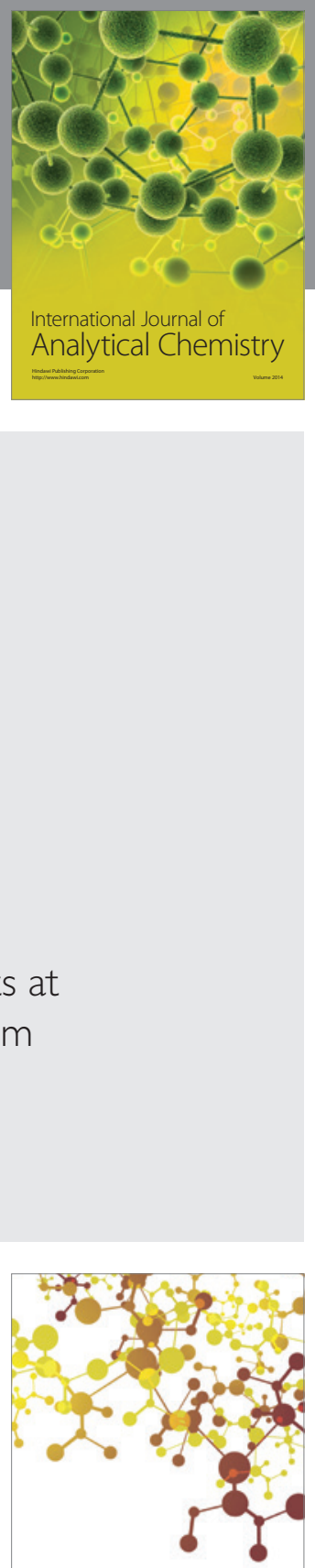

Journal of

Applied Chemistry
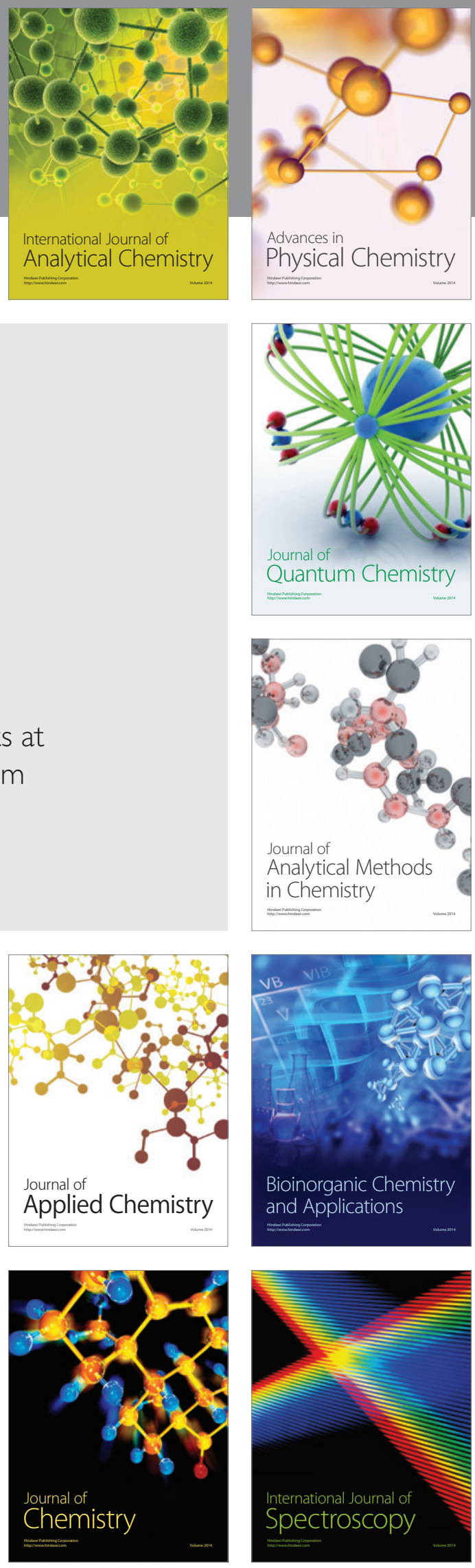